\title{
AN INTRODUCTORY REVIEW OF METHODS FOR THE ARTICULATION OF STRATEGY IN DESIGN
}

\author{
Simeone, Luca \\ Aalborg University
}

\begin{abstract}
This paper presents an introductory review of methods to articulate strategy in design. Articulation is here seen as a process in which strategy is more or less strictly and explicitly identified and described, e.g. in relation to key ideas, directions to follow, goals and expected results. The paper surveys existing literature in design research and identifies two broad categories of methods for the articulation of strategy: (1) structured frameworks, and (2) vocabularies and principles.
\end{abstract}

Keywords: Design methods, Design management, Design methodology, Strategy, Strategic Design

Contact:

Simeone, Luca

Aalborg University

Department of Architecture, Design, and Media Technology

Denmark

1si@create.aau.dk 


\section{INTRODUCTION}

Strategy is a central theme frequently explored by design researchers and practitioners both within academic venues (Borja de Mozota, 1998; Cooper et al., 2011; Heskett, 2017; Nixon, 2016) and in outlets for broader public, including books (Holston, 2011), introductory articles (Ignatius, 2015) and e-zines produced by firms specialized in strategy consulting ${ }^{1}$. This attention has also been fuelled by a general widespread use of the term strategy (Kenny, 2018). No agreed-upon definitions of strategy exist (Hambrick and Fredrickson, 2005), even though there is some convergence in characterizing it as "maintaining a balance between ends, ways, and means; about identifying objectives; and about the resources and methods available for meeting such objectives" (Freedman, 2013, p. xi) or, in other terms, "the core of strategy work is always the same: discovering the critical factors in a situation and designing a way of coordinating and focusing actions to deal with those factors" (Rumelt, 2011, p. 3). Within the design field, definitions of the word differ, even though recurrent components of strategy can be considered: (1) being aware of resources and capabilities (Barney, 2001; Eisenhardt and Martin, 2000; Teece et al., 1997) in the designer's hands and knowing where to direct effort and energies, (2) the related ability to frame complex problems as to identify a set of objectives that can be realistically reached (Rumelt, 2011), (3) being aware of the competitive context and the limiting circumstances in which our actions unfold, e.g. competitors or external factors that might affect our plans (Mintzberg, 1994) and (4) the processes for defining and implementing sets of actions that take into consideration all the above (Echevarria, 2017). Within design research, a consensus and quite ample definition of strategy emerging from a survey of literature has been characterized as about "finding a balance between ends, means and ways while keeping an eye on risks as to achieve the impact needed to address a challenge" (Simeone et al., 2019).

Oftentimes, existing design research has been carried out under the rubrics of strategic design or design strategy. Giulia Calabretta and colleagues define strategic design as the "professional field in which designers use their principles, tools and methods to influence strategic design-making within an organization. Strategic decisions include those decisions that have a long term impact for companies, involve several stakeholders and require a substantial commitment of monetary and non-monetary resources" (Calabretta et al., 2016, p. 9). In order to achieve greater impact, design needs to be deeply integrated within the organization processes, functions, culture (Cooper et al., 2011). As such, from the perspective of design management, appropriate design strategies should establish "how an organisation intends to use design, and how design processes can best serve its operational needs" (Best, 2006, p. 49) and can be used to identify, manage and form plans "according to the company's vision, business mission, product portfolio and market situations" (Baggerud et al., 2006, p. 140). Rather than specifically look into the distinction between strategic design and design strategy, this paper intends to keep a broader focus on methods to consider some strategic aspects of design projects and processes.

While there is a consensus on the importance of considering the strategic aspects of design processes (Borja de Mozota, 2003; Boztepe, 2016; Heskett, 2017; Kotler and Rath, 1984; Lockwood and Walton, 2008), the recommended approaches vary from structured frameworks (Boeijen et al., 2014; Boyer et al., 2011; Calabretta et al., 2016; Nixon, 2016), up to the adoption of strategic design vocabularies (Hill, 2012) or design principles (Kempenaar and van den Brink, 2018). The scope of this paper is to propose an introductory review of a particular subset of such different methods, the ones oriented towards strategy articulation. With this term, we refer to those processes in which strategy is more or less strictly and explicitly identified and described, e.g. in relation to key ideas, directions to follow, goals and expected results (Love et al., 2002). In this sense, articulation is regarded as a discursive practice in which representations of what the organization "has been, is, and will be doing" (Mirabeau and Maguire, 2014, p. 1219) are formulated, but also circulated among stakeholders and subjected to their various interpretations. Rather than considering these processes as confined to the initial phases of a project, strategy articulation should be seen as an iterative process in which strategy is continuously re-evaluated and re-adjusted along the way and in relation to the impact of external and unpredictable factors

${ }^{1}$ E.g. McKinsey Quarterly (https://www.mckinsey.com/quarterly/overview), Boston Consulting Group's Idea and inspiration newsletter (https://www.bcg.com/bcg-henderson-institute/thought-leadership-ideas.aspx), Bain \& Company's Insights newsletter (https://www.bain.com/) all contain references to the potential of design and/or design thinking for strategy definition and execution. 
(Liedtka, 2002; McCullagh, 2008; Mintzberg, 1978). In addition, different applications of strategy in design (e.g. a strategy for a new design product line or a strategy to use a design approach within an organization) might call for different and specific methods for strategy articulation. While acknowledging this complexity, this paper is built on two premises: (1) it specifically focuses on the initial phases of strategy articulation where the broad characterizations of strategy presented above (Rumelt, 2011; Freedman, 2013; Simeone et al., 2019) can be used, and (2) it solely examines the specific aspect of strategy articulation and, thus and deliberately, does not look into the existing rich literature in how strategy can be continuously re-articulated, fine-tuned, put at play and executed within organizations (Borja de Mozota, 2003; Cooper et al., 2011; Svengren Holm, 2011).

\section{RESEARCH METHODOLOGY}

Rather than aiming at a definite and exhaustive mapping of all the methods for the articulation of strategy in design, this paper proposes an introductory overview of such methods, which revolves around two main categories: (1) structured frameworks, and (2) vocabularies and principles. This categorization emerged by analyzing and clustering a variety of sources (i.e. mostly books and articles related to strategic design, design strategy and design management) through a concept-centric framework (Webster and Watson, 2002). The term 'method' is here used as to quite broadly refer to "a way, technique, or process of or for doing something" (Merriam-Webster.com Dictionary, n.d.). As such, the term is deemed as ample enough to also include the above-mentioned category of 'vocabularies and principles', even though the use of vocabularies and principles in strategy is a quite diverse endeavor than the application of the more structured and systematic processes, procedures and techniques comprised under the umbrella of the category 'structured frameworks'.

The selection of literature was not carried out with the intention of systematically reviewing all the contributions related to strategic design or design strategy. Rather, we aimed at presenting some design research contributions that - in our judgment - could be taken as examples of different methods for strategy articulation. In most cases, the reviewed works did not specifically use the term 'strategy articulation', but rather terms such as formulation, definition, specification, development of strategy and similar. We are aware that each of these terms comes with a quite different and specific meaning and, as such, looking at them under the same umbrella construct of 'strategy articulation' can be considered an arbitrary move. Hopefully, though, the already presented definition of strategy articulation (i.e. strategy identification and description in relation to key ideas, directions to follow, goals and expected results) adopted for this paper is plastic enough to accommodate some of the differences in terminology. Such difference also stems from the fact that some of the methods more strictly refer to specific design processes (e.g. product design) while some other methods are more general and can be applied to broader contexts (e.g. the articulation of a design-based company strategy). In addition, some of the presented methods go beyond the phase of articulation and also refer to phases of strategy execution. Even though these methods are included in the selection, the main focus of the paper remains on the initial phase of strategy articulation.

The design literature presented in the paper stems from an analysis of contributions coming from books, conferences and journals (Gemser et al., 2012; Mansfield, 2016) in the design field. The final selection of the sources presented in this paper might offer a preliminary overview of the variety of approaches proposed by designer researchers and practitioners and, thus, serve as a departing point for further and more focused analyses. As such, the paper aims at complementing existing systematic studies that examine how design can support strategy formulation and implementation (e.g. the work of Stevens and Moultrie, 2011).

\section{KEY FINDINGS}

\subsection{Structured frameworks}

A good number of authors argued that strategy articulation in design can be supported by somewhat predefined sequences of methods (this is what, in this paper, is termed as 'structured frameworks'). 
Quite common is the use of rational frameworks of analysis borrowed from corporate strategy such as Five Forces ${ }^{2}$ (Borja de Mozota, 1998; Grundy, 2006), SWOT ${ }^{3}$ or PESTEL ${ }^{4}$ (Ho, 2014). For example, in his book The strategic designer, David Holston proposed a process for strategy identification articulated into four steps: (1) objectives are set taking into account the organization's vision and mission statements, its SMART (specific, measurable, achievable, realistic, time based) goals and the need to focus on a limited set of actions in relation to the available resources; (2) the organization is analysed in relation to its strengths and weaknesses in the light of the opportunities and the threats in the environment (SWOT analysis); (3) competitors are studied and benchmarked; (4) the wider context is examined (through PESTEL and Five Forces) (Holston, 2011). The author also briefly discussed how organizational alignment, action plans and measurement (for example, through balanced scorecards ${ }^{5}$ ) can be used for strategy implementation.

The adoption of methods from corporate strategy is also quite common in manuals presenting methods for design and design thinking (e.g. Curedale, 2015; Kumar, 2014). Some of these works also present complementary design-specific approaches such as the 'strategy wheel' to review and measure company's capabilities (Boeijen et al., 2014).

In her edited volume Strategic Design Thinking, Natalie Nixon looked at strategic design as "the process of developing strategy as informed by the design thinking processes" (Nixon, 2016, p. xiii). The contributions of the book explore the nexus between design thinking and business strategy and, generally, make the case for a stricter integration of design and business. In a chapter titled Tools for Strategic Design, the design consultant Cindy Tripp proposed a variety of design methods based on diagrams, canvases, design games that can be used to frame and define strategies by collecting data, analysing it from multiple perspectives, identifying patterns and elaborating and visualizing strategies (Tripp, 2016).

Giulia Calabretta and colleagues (Calabretta et al., 2016) presented eight essential design practices (envisioning, inspiring, simplifying, structuring, aligning, translating, embracing and educating) that represent a sequential approach for strategic design processes. The focus of their work is not only on how to implement these practices, but also on how to support a way of thinking that is more strategic precisely because it takes into consideration broad contexts of application (e.g. the organizational, managerial and business components of a design project). As such, the authors proposed a structured approach that strategic designers can follow to contribute to defining an organization's vision and to driving organizational decisions, practices and behaviours.

Rachael Gould and colleagues proposed a logical framework in the form of a decision-support prototype that provides information on the business and sustainability value of different sustainable product design strategies and helps project teams to select which strategies to adopt (Gould et al., 2017).

Nigel Cross defined design strategy as "the general plan of action for a design project and the sequence of particular activities (i.e. the tactics or design methods) which the designer or the design team expect to undertake to carry out the plan" (Cross, 2008, p. 193) and noted that the purpose of having a strategy is "to ensure that activities remain realistic with respect to the constraints of time, resources, etc., within which the design team has to work" (Cross, 2008, p. 193). To this end, Cross argued that a design strategy should be articulated into a framework of intended actions (i.e. specific combinations of methods and techniques like the ones in Figure 1) and a management control function to adapt these actions along the way. Such an approach takes into account the potential impact of external and unpredictable factors and the need to adapt and realign strategies along the way.

\footnotetext{
${ }^{2}$ Porter proposed that to analyze an industry, five forces has to be taken into consideration ("five forces framework"): competitive rivalry between firms, bargaining power of suppliers and of buyers, threats of new entrants and of substitute offerings (Porter, 1980, 1996).

${ }^{3}$ Kenneth Andrews emphasized the importance of case-specific strategies (Freedman, 2013), which take into consideration a variety of factors that can be examined through methods such as the SWOT analysis (Strengths and Weaknesses of an organization in light of the Opportunities and Threats in the environment). Andrews assumed that, in strategy, careful thought should precede rational action and implementation (Andrews, 1971).

${ }^{4}$ The PESTEL is a method to analyse some of the contextual factors affecting strategy: Political, Economic, Social, Technological, Ecological and Legal factors (Johnson et al., 2017).

5 The Balanced Scorecard translates a company's vision and strategy into a coherent set of performance measures (Norton and Kaplan, 1996).
} 


\begin{tabular}{|ll|}
\hline $\begin{array}{l}\text { Stage } \\
\text { 1. Recognition }\end{array}$ & $\begin{array}{l}\text { Tactics to be used } \\
\text { User scenarios. } \\
\text { Brainstorming. }\end{array}$ \\
& $\begin{array}{l}\text { Objective tree. } \\
\text { Information search. } \\
\text { Function analysis. }\end{array}$ \\
& $\begin{array}{l}\text { Taking a holiday. } \\
\text { Talking the problem over with colleagues and friends. } \\
\text { Tackling another problem. }\end{array}$ \\
& $\begin{array}{l}\text { Enlarging the search space: counter-planning. } \\
\text { 4. Illumination }\end{array}$ \\
& $\begin{array}{l}\text { Morphological chart. } \\
\text { Brainstorming. } \\
\text { Enlarging the search space: random input. }\end{array}$ \\
& $\begin{array}{l}\text { Performance specification. } \\
\text { 5. Verification }\end{array}$ \\
& Weighted objectives. \\
\hline
\end{tabular}

Figure 1. Framework based on a procedural model of the design process (Cross 2008)

Along similar lines, Bryan Boyer and colleagues of the former Helsinki Design Lab (an initiative by Sitra, The Finnish Innovation Fund, to advance strategic design) presented their recipes for systemic change, which revolve around the Studio Model, a "specific process that benefits from the attitude, approach and abilities of strategic design" (Boyer et al., 2011, p. 87) and that is built around practices that favour multistakeholder co-design sessions, immersive field visits, reviews and critique. The kernel of these practices is a strategic approach that starts with the identification of a vision and continues throughout the entire duration of a project (and beyond) through an activity of stewardship that is also oriented toward continuously readapting strategic action (Figure 2).

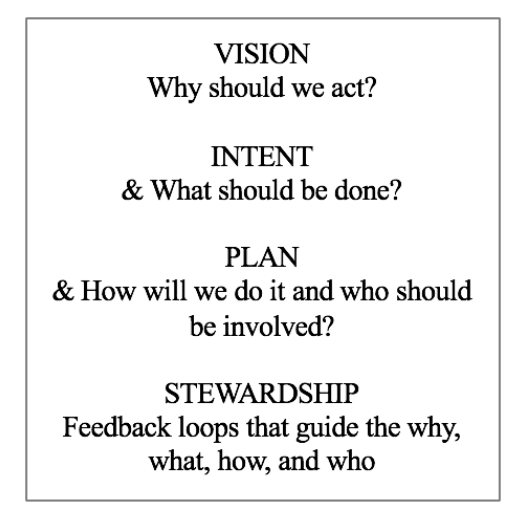

Figure 2. Strategic approach behind design projects/processes (Boyer et al., 2011)

All these approaches build on a conceptualization that praises the logical structure and the coherence of strategy (Rumelt, 2011).

\subsection{Vocabularies and principles}

Henry Mintzberg proposed a view of strategy as a "pattern in a stream of decisions" (Mintzberg, 1994, p. 934). His point was that strategic planners cannot have enough foresight to fully anticipate future courses of actions and external events (Mintzberg, 1994). Therefore, there are "deliberate" and "emergent" strategies (thus, deliberate or emergent patterns of actions). A deliberate strategy depends on a clear, precise and often centralized definition of intentions and plans. This deliberate strategy can be successfully executed when no interference from external forces (market, politics, technology) or events occur. Conversely, in situations when the influence of external and unpredictable factors is significant, strategy emerges from a sequence of context-dependent decisions made by managers or other individuals while trying to respond to the constraints and imperatives imposed by the external environment. Therefore, organizations should always be alert in observing the results of their decisions and in continuously trying to react to unanticipated outcomes.

In such perspective, design strategy "is not about grand conceptual ideas but it is instead a pragmatic blend of thinking ahead and en-route adaptation" (McCullagh, 2008, p. 67). Specifically referring to Mintzberg, Keving McCullagh argued against the view of strategy as a top down rational and detached 
planning and stated that "strategy emerges through interplay between structured planning and ad hoc responses" (McCullagh, 2008, p. 72).

Systemic views on strategy prompted scholars in looking at strategic design as aimed at "conferring to social and market bodies a system of rules, beliefs, values and tools to deal with the external environment, thus being able to evolve (and so to survive successfully) as well as maintaining and developing one's own identity. And, in doing so, influencing and changing the environment too" (Meroni, 2008, p. 31)

The idea that strategy cannot be entirely pre-planned or controlled through structured frameworks has inspired design researchers and practitioners in proposing different approaches to strategy articulation. Some authors highlighted the need to embrace multiple viewpoints to look at the complexity of design interventions. Mieke van der Bijl-Brouwer and Kees Dorst proposed a model that links human-centered design and strategic innovation and that can be used to analyse design projects and processes through different frames (van der Bijl-Brouwer and Dorst, 2017). Such frames - i.e. ways of looking at the project or the process from different angles - are based on a model (Figure 3) that examines human Needs and Aspirations for application in a Design and Innovation process (thus the acronym 'NADI').

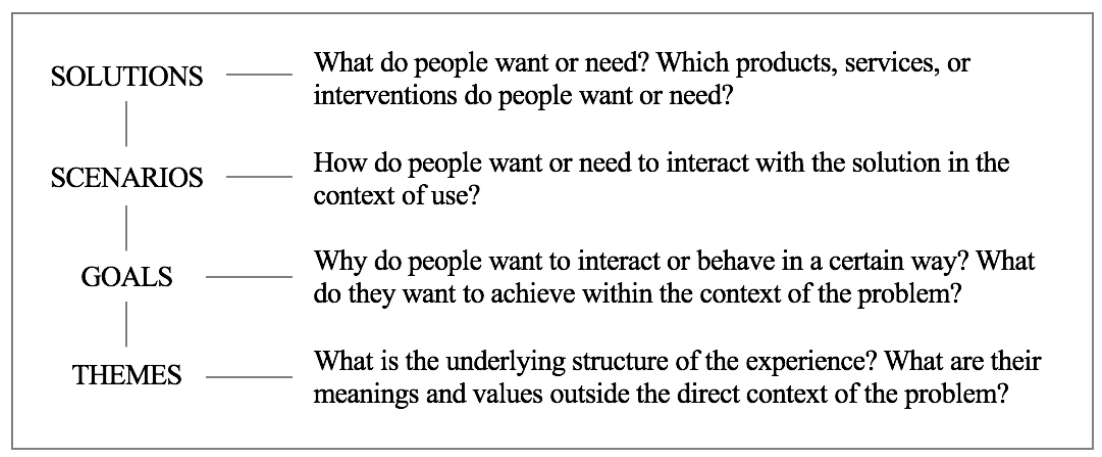

Figure 3. The NADI-model (van der Bijl-Brouwer and Dorst, 2017)

The NADI-model distinguishes two levels of 'whys' that contribute to design and innovation in different ways. As argued by van der Bijl-Brouwer and Dorst, "[t]he deepest levels of insights are the goals and themes levels, which describe why people want or need certain solutions and scenarios. The difference between goals and themes is that goals describe what people want to achieve within the context of a certain design problem, while the themes describe the underlying needs and aspirations that can be analysed independently of that context" (van der Bijl-Brouwer and Dorst, 2017, pp. 9-10). Frames are also a central element of the theorization of Francesco Zurlo and Cabirio Cautela, who examined how narrative frames in different innovation and organizational contexts affect design approaches and strategies (Zurlo and Cautela, 2014). Anna Meroni developed some considerations on the capacity of strategic designers to interpret, frame and operate in complex situations: "Contribuing to change (in a collectivity, a community, an enterprise) the understanding of a problem, to work out a new perception and vision, to build capacity to implement it, creating a platform of tools and knowledge, enabling and empowering people to do things and deal with a changing context, is the real and profound meaning of any strategic design project" (Meroni, 2008, p. 36).

Dan Hill proposed a vocabulary that designers can use as a lens to look at the strategic aspects of their design processes. This vocabulary is composed of concepts such as "platform", "installations", "code", "adaptive layers" that invite designers to conceive their projects as scalable, replicable and malleable (Hill, 2012). A key concept is the one of "dark matter". The dark matter is what typically remains amorphous and nebulous in the background of design processes and yet can dramatically and powerfully affect the outcomes: "organisational culture, policy environments, market mechanisms, legislation, finance models and other incentives, governance structures, tradition and habits, local culture and national identity, the habitats, situations and events that decisions are produced within" (Hill, 2012, p. 83). Although designers cannot have a full control of such dark matter, they still have to take it into consideration while planning and executing their projects. Language is also a central element of Hernan Casakin's work, which looked into how associative thinking - e.g. the use of metaphors in design problem solving - can help designers to reflect on a situation from a new perspective by also considering information that is not directly related to that situation (Casakin, 2011). 
In one way or another, all these authors suggested that besides (or as an alternative of) structured frameworks, the articulation of strategy has to do with particular ways of looking at and framing complex areas of intervention.

A complementary approach is the one proposed by Annet Kempenaar and Ari van den Brink in some reflections centred around landscape architecture. Kempenaar and van den Brink characterized strategic design as "the involvement of design in vision development and strategy formulation" (Kempenaar and van den Brink, 2018, p. 81) by referring to the work of those design researchers such as Ezio Manzini (Manzini, 2015) or John Thackara (Thackara, 2005) - that focused on how design can contribute toward a transition to a sustainable society. In practice, Kempenaar and van den Brink argued that the strategic dimension of design emerges from the application of some design principles to design projects. By interviewing a number of landscape architects, the authors identified seven principles that these architects keep in mind while creating regional designs for specific situations. These principles are: "taking a dynamic systems perspective, addressing multiple geographical scales, looking from history to future, creating a continuing dialogue with stakeholders, reframing the region, sensing and responding, balancing direction and openness" (Kempenaar and van den Brink, 2018, p. 85). Rather than following predefined structured frameworks, it is by keeping in mind these principles that architects can strategically steer the design process and select contextspecific methods, techniques and design skills to face problems that might be ill-defined, complex, fuzzy and volatile. In a similar vein, from a perspective crossing architecture, urban and regional planning, John Friend and Allen Hickling viewed planning as "a continuous process: a process of choosing strategically through time" (Friend and Hickling, 2012, p. 1). Their point is that long-term plans are actualized by day-to-day decisions and both plans and decisions are affected by pressure of urgency, competition for resources, turbulence and complexity in the world, cognitive and emotional overload, uncertainty and confusion, interorganizational and organizational conflict. The dilemma of such strategic practice is that planning and day-to-day choices emerge from a continuous tension between two sets of polarities: (a) reducing uncertainty, simplifying complexity, aiming at a focused scope, adopting a more decisive approach and reacting to eventual conflicts and (b) accommodating uncertainty, elaborating complexity, aiming at a broader, synoptic scope, adopting a more exploratory approach and fostering a more interactive (and oriented to collaboration) treatment of conflicts. This is why Friend and Hickling argued that strategy should embrace dilemmas and complexity rather than aim for linearity, objectivity, certainty and comprehensiveness.

\section{DISCUSSION AND FINAL REMARKS}

As with any categorization, the boundaries we used to distinguish 'structured frameworks' and 'vocabularies and principles' set some clear-cut distinctions that do not render justice to the more nuanced positioning of some of the reviewed works. While we acknowledge the somewhat arbitrary nature of this categorization, we believe that the two categories are a helpful means to look at scholarly work from different angles. In addition, rather than see frameworks, principles and vocabularies as incompatible, we consider them as approaches that can be combined in order to address the respective shortcomings.

Structured frameworks grasped the attention of researchers and practitioners as they offer approaches that can be readily deployed and systematically replicated. Structured frameworks provide an actionable sequence of steps that can guide the process of strategy articulation in defining visions, directions to follow, goals and expected results. However, there are some important aspects to which not all the structured frameworks give enough consideration. Firstly, the emergent nature of strategy is not always properly acknowledged. Especially at the initial stages of a project, strategic planners cannot have enough foresight to anticipate future courses of actions and external events. Unforeseen circumstances might require a continuous process of strategy adjustment on-the-fly (Raynor, 2007). Not all the presented structured frameworks for the articulation of strategy are flexible enough to be applied and reapplied in different phases of a project and, possibly, in a quite agile and adaptable manner.

Secondly, another limiting aspect of some (but not all) of the proposed structured frameworks is that they rely on tools such as predefined and fixed canvases or similar interpretive templates that tend to reduce complexity as to make complex challenges more actionable. However, one way to tackle complex challenges is, instead, precisely to acknowledge this complexity and try to make sense of it through nuanced, multi-perspectival and fine-grained representations (Friend and Hickling, 2012). For example, 
one particular element that does not seem often represented in structured frameworks is the idea that strategy only comes into the play as a result of power dynamics, alliances, ambiguity and deception (Gaddis, 2018; Paret, 1986). Strategy is a political art, whose important components are "bargaining and persuasion as well as threats and pressure" (Freedman, 2013, p. xii). Some works (e.g. Calabretta et al., 2016) use some constructs - such as the one of design as translation (Simeone, 2016) - that could be further developed as to more fully show such ambiguous and relational aspects of strategy. However, these aspects are generally not central in the structured frameworks analysed in this paper.

Thirdly, in some cases, structured frameworks use an array of tools or methods uncritically and hastily imported from corporate strategy without paying much attention to the way in which these tools and methods been modified over time or criticized in that field. For example, the criticism that some of the proposed methods (e.g. SWOT or Five Forces) received for being too simplistic (Grundy, 2006) and reductionist (Menon et al., 1999), unclear, ambiguous or simply "ineffective as a means of analysis or as part of a corporate strategy review" (Hill and Westbrook, 1997, p. 50) is often not even mentioned within design research.

Vocabularies and principles acknowledge the complexity of design interventions and thus propose that design strategies should be plastic enough to accommodate local contexts of interventions. Vocabularies, such as the one proposed by Hill (2012), can enable particular ways of looking at and framing complex areas of intervention. Vocabularies can enrich the way in which complexity is represented without oversimplifying it. Principles can offer an overall orientation to a design project without being as normative as a structured framework. In other terms, principles and vocabularies tend to look at the processual dimension of articulation. As the cultural anthropologist James Clifford put it, articulation "is the political connecting and disconnecting, the hooking and unhooking of elements" (Clifford, 2003, p. 45). Or, as suggested by Stuart Hall, an articulation is "the form of the connection that can make a unity of two different elements, under certain conditions. It is a linkage which is not necessary, determined, absolute and essential for all time" (in Grossberg, 1986, p. 53). As such, articulation of strategy can be seen as a process in which elements such as key ideas, direction to follow, goals and expected results are only preliminarily defined at the beginning of a project and then continuously renegotiated and readapted in relation to the various forces at play. However, the downside of vocabularies and principles is that they do not propose easy suggestions on how to operationalise processes for the articulation of strategy in design and this can be a limiting factor as it makes it difficult to set up articulation processes that can be readily deployed, replicated and also evaluated against standards.

As such, a combination of some of the structured frameworks presented in the previous pages possibly, the ones that do not make too much use of externally and uncritically imported tools and methods - and a set of vocabularies and principles would probably offer some advantages in a number of cases. A structured framework would provide an actionable sequence of steps and strategic vocabularies would help to frame the challenge and think through possible solutions without excessively reducing complexity. A set of strategic principles would provide an overall orientation during the initial phase of strategy articulation but would also help rearticulate strategy in an agile and emergent manner throughout the entire duration of the project. However, we are not aware of many studies that tested this integration in practice and, as such, these reflections are only theoretical. There might as well be situations in which this integration of structured frameworks, vocabularies and principles is not ideal or productive.

One aspect that surely deserves more consideration - and that is only very briefly touched by this paper is the idea that different and integrative methods might be needed in relation to different contexts of applications. On the one hand, some of the methods are in this review only superficially presented. A closer look, for example, at the frameworks of Calabretta and colleagues (2016) and Boyer and colleagues (2011) would show how these frameworks suggest an array of methods that can be used for specific contexts of applications (e.g. business plan modelling, participatory design sessions, etc.). On the other, this paper only deliberately focused on the initial phases of strategy articulation, in which the reviewed methods can be used to identify a preliminary strategy, broadly characterized in the abovementioned definition as "finding a balance between ends, means and ways while keeping an eye on risks as to achieve the impact needed to address a challenge". Departing from this initial articulation, at later stages, strategy needs to be continuously re-articulated in relation to the specific contexts of applications. A strategy for a new design product line would call for different articulation methods than, for example, a strategy to implement design processes within an organization. The methods reviewed in this paper 
might then need to be integrated by additional and more specific methods (e.g. methods to work at a more fine-grained level on the business aspects of a design project or methods to map the motivations of different stakeholders, just to make some examples).

We believe that this complexity renders this area of research particularly fruitful. This paper might act as a departing point for further and more fine-grained analyses that could look at more practical applications of structured frameworks, vocabularies and principles and more closely examine differences and possibilities for integration.

\section{REFERENCES}

Andrews, K. (1971), The Concept of Corporate Strategy, R.D. Irwin, Homewood, IL.

Baggerud, B., Nesbakken, R. and Liem, A. (2006), "Design Strategy - A Starting Point for Integrated Product Development.", Proceedings of NordDesign, presented at the NordDesign, Reykjavik, Iceland.

Barney, J. (2001), "Resource-based theories of competitive advantage: A ten-year retrospective on the resourcebased view", Journal of Management, Vol. 27, pp. 643-650.

Best, K. (2006), Design Management: Managing Design Strategy, Process and Implementation, AVA Publishing, Lausanne.

van der Bijl-Brouwer, M. and Dorst, K. (2017), "Advancing the strategic impact of human-centred design", Design Studies, Vol. 53, pp. 1-23.

Boeijen, A. van Daalhuizen, J., Schoor, R. van der and Zijlstra, J. (2014), Delft Design Guide: Design Strategies and Methods, BIS Publishers, Amsterdam.

Borja de Mozota, B. (1998), "Structuring Strategic Design Management: Michael Porter's Value Chain”, Design Management Journal, Vol. 9 No. 2, pp. 26-31.

Borja de Mozota, B. (2003), Design Management: Using Design to Build Brand Value and Corporate Innovation, Allworth Press, New York.

Boyer, B., Cook, J.W. and Steinberg, M. (2011), Recipes for Systemic Change, Sitra/Helsinki Design Lab, Helsinki (Finland).

Boztepe, S. (2016), "Design Expanding into Strategy: Evidence from Design Consulting Firms", Proceedings of Design Research Society Conference, presented at the DRS2016, Brighton, Uk.

Calabretta, G., Gemser, G. and Karpen, I. (Eds.). (2016), Strategic Design: 8 Essential Practices Every Strategic Designer Must Master, BIS Publishers, Amsterdam.

Casakin, H. (2011), "Associative thinking as a design strategy and its relation to creativity", Proceedings of ICED, presented at the ICED, Copenhagen, Denmark.

Clifford, J. (2003), On the Edges of Anthropology, Prickly Paradigm Press, Chicago.

Cooper, R., Junginger, S. and Lockwood, T. (Eds.). (2011), The Handbook of Design Management, Bloomsbury Academic, Oxford and New York.

Cross, N. (2008), Engineering Design Methods: Strategies for Product Design, 4th ed., Wiley, Chichester.

Curedale, R. (2015), 50 Selected Design Methods: To Transform Your Design, 2nd ed., Design Community College, Topanga, CA.

Echevarria, A.J. (2017), Military Strategy: A Very Short Introduction, Oxford University Press, Oxford; New York.

Eisenhardt, K.M. and Martin, J.A. (2000), “Dynamic capabilities: what are they?", Strategic Management Journal, Vol. 21 No. 10-11, pp. 1105-1121.

Freedman, L. (2013), Strategy: A History, Oxford University Press, Oxford, New York.

Friend, J. and Hickling, A. (2012), Planning Under Pressure, 3rd edition., Routledge, Abingdon, Oxon.

Gaddis, J.L. (2018), On Grand Strategy, Penguin Press, New York.

Gemser, G., de Bont, C., Hekkert, P. and Friedman, K. (2012), "Quality perceptions of design journals: The design scholars' perspective”, Design Studies, Vol. 33 No. 1, pp. 4-23.

Gould, R., Lagun Mesquita, P., Bratt, C. and Broman, G. (2017), "Why choose one sustainable design strategy over another: a decision-support prototype", Proceedings of ICED, presented at the ICED, Vancouver, Canada.

Grossberg, L. (1986), "On Postmodernism and Articulation An Interview with Stuart Hall”, Journal of Communication Inquiry, Vol. 10 No. 2, pp. 45-60.

Grundy, T. (2006), "Rethinking and reinventing Michael Porter's five forces model", Strategic Change, Vol. 15 No. 5, pp. 213-229.

Hambrick, D.C. and Fredrickson, J.W. (2005), “Are you sure you have a strategy?”, Academy of Management Executive, p. 13.

Heskett, J. (2017), Design and the Creation of Value, edited by Dilnot, C. and Boztepe, S., Bloomsbury, New York. Hill, D. (2012), Dark Matter and Trojan Horses. A Strategic Design Vocabulary, Strelka Press.

Hill, T. and Westbrook, R. (1997), "SWOT analysis: it's time for a product recall", Long Range Planning, Vol. 30 No. 1, pp. 46-52.

Ho, J.K.-K. (2014), "Formulation of a systemic PEST analysis for strategic analysis", European Academic Research, Vol. 2 No. 5, pp. 6478-6492. 
Holston, D. (2011), The Strategic Designer, How Books, Cincinnati.

Ignatius, A. (2015), "Design as Strategy”, Harvard Business Review, No. September 2015.

Johnson, G., Whittington, R., Scholes, K., Angwin, D. and Regnér, P. (2017), Fundamentals of Strategy, 4th edition., Pearson Education.

Kempenaar, A. and van den Brink, A. (2018), "Regional designing: A strategic design approach in landscape architecture", Design Studies, Vol. 54, pp. 80-95.

Kenny, G. (2018), "Your Strategic Plans Probably Aren’t Strategic, or Even Plans”, Harvard Business Review, available at: https://hbr.org/2018/04/your-strategic-plans-probably-arent-strategic-or-even-plans (accessed 8 May 2018).

Kotler, P. and Rath, A.G. (1984), "Design: A powerful but neglected strategic tool”, Journal of Business Strategy, Vol. 5 No. 2, pp. 16-21.

Kumar, R. (2014), "Managing Ambiguity in Strategic Alliances”, California Management Review, Vol. 56 No. 4 , pp. 82-102.

Liedtka, J. (2002), “In Defense of Strategy as Design”, California Management Review, Vol. 42 No. 3, pp. 8-30.

Lockwood, T. and Walton, T. (Eds.). (2008), Building Design Strategy, Allworth Press, New York.

Love, L.G., Priem, R.L. and Lumpkin, G.T. (2002), "Explicitly Articulated Strategy and Firm Performance Under Alternative Levels of Centralization”, Journal of Management, Vol. 28 No. 5, pp. 611-627.

Mansfield, N.J. (2016), "Ranking of Design Journals Based on Results of the UK Research Excellence Framework: Using REF as Referee", The Design Journal, pp. 1-17.

Manzini, E. (2015), Design, When Everybody Designs: An Introduction to Design for Social Innovation, The MIT Press, Cambridge, Massachusetts.

McCullagh, K. (2008), "Strategy for the Real World”, in Lockwood, T. and Walton, T. (Eds.), Building Design Strategy, Allworth Press, New York, pp. 67-78.

Menon, A., Bharadwaj, S.G., Adidam, P.T. and Edison, S.W. (1999), “Antecedents and consequences of marketing strategy making: a model and a test”, The Journal of Marketing, pp. 18-40.

Meroni, A. (2008), "Strategic design: where are we now? Reflection around the foundations of a recent discipline”, Strategic Design Research Journal, Vol. 1 No. 1, pp. 31-38.

Mintzberg, H. (1978), "Patterns in Strategy Formation”, Management Science, Vol. 24 No. 9, pp. 934-948.

Mintzberg, H. (1994), “The Fall and Rise of Strategic Planning”, Harvard Business Review, No. JanuaryFebruary 1994, available at: https://hbr.org/1994/01/the-fall-and-rise-of-strategic-planning (accessed 27 March 2018).

Mirabeau, L. and Maguire, S. (2014), "From autonomous strategic behavior to emergent strategy: From Autonomous Strategic Behavior to Emergent Strategy", Strategic Management Journal, Vol. 35 No. 8, pp. 1202-1229.

Nixon, N.W. (Ed.). (2016), Strategic Design Thinking, Bloomsbury, New York; London.

Norton, D.P. and Kaplan, R.S. (1996), The Balanced Scorecard: Translating Strategy Into Action, Harvard Business School Press, Boston.

Paret, P. (Ed.). (1986), Makers or Modern Strategy, Princeton University Press, Princeton, N.J.

Porter, M.E. (1980), Competitive Strategy Techniques for Analyzing Industries and Competitors, The Free Press, New York.

Porter, M.E. (1996), "What is Strategy", Harvard Business Review, Vol. 74 No. 6, pp. 61-78.

Raynor, M.E. (2007), The Strategy Paradox: Why Committing to Success Leads to Failure, Doubleday, New York.

Rumelt, R. (2011), Good Strategy, Bad Strategy, Crown Business, New York.

Simeone, L. (2016), Design Moves. Translational Processes and Academic Entrepreneurship in Design Labs, Malmö University, Malmö, Sweden, available at: https://dspace.mah.se/handle/2043/21426.

Simeone, L., Drabble, D., Iacopini, G., Van Dam, K., Morelli, N., De Götzen, A. and Cullen, J. (2019), "Articulating a strategic approach to face complexity in design projects: The role of Theory of Change", Proceedings of the Academy for Design Innovation Management Conference, London, UK.

Stevens, J. and Moultrie, J. (2011), “Aligning Strategy and Design Perspectives: A Framework of Design's Strategic Contributions", The Design Journal, Vol. 14 No. 4, pp. 475-500.

Svengren Holm, L. (2011), "Design Management as Integrative Strategy", in Cooper, R., Junginger, S. and Lockwood, T. (Eds.), The Handbook of Design Management, Berg, Oxford and New York, pp. 294-315.

Teece, D.J., Pisano, G. and Shuen, A. (1997), "Dynamic Capabilities and Strategic Management”, Strategic Management Journal, Vol. 18 No. 7, pp. 509-533.

Thackara, J. (2005), In the Bubble: Designing in a Complex World, MIT Press, Cambridge Mass.

Tripp, C. (2016), “Tools for Strategic Design”, in Nixon, N.W. (Ed.), Strategic Design Thinking, Bloomsbury, New York; London, pp. 91-113.

Webster, J. and Watson, R.T. (2002), “Analyzing the past to prepare for the future: Writing a literature review", MIS Quarterly, pp. xiii-Xxiii.

Zurlo, F. and Cautela, C. (2014), "Design Strategies in Different Narrative Frames”, Design Issues, Vol. 30 No. 1, pp. 19-35. 